\title{
Editorial \\ Editorial for the Launching of Mining Journal
}

\author{
Mostafa Benzaazoua (iD
}

check for updates

Citation: Benzaazoua, M. Editorial for the Launching of Mining Journal. Mining 2021, 1, 1-5. https://doi.org/ $10.3390 /$ mining 1010001

Received: 9 November 2020

Accepted: 9 November 2020

Published: 24 November 2020

Publisher's Note: MDPI stays neutral with regard to jurisdictional claims in published maps and institutional affiliations.

Copyright: (C) 2020 by the author. Licensee MDPI, Basel, Switzerland. This article is an open access article distributed under the terms and conditions of the Creative Commons Attribution (CC BY) license (https:// creativecommons.org/licenses/by/ $4.0 /)$.
Research Institute in Mining and Environment, University of Quebec (RIME-UQAT), Rouyn-Noranda, QC J9X 5E4, Canada; Mostafa.Benzaazoua@uqat.ca

Worldwide, the mining industry played a very important role in the first industrial revolution during the previous century. This was possible due to the many technological advances throughout the whole mining life cycle, which include exploration techniques, mining methods, and ore processing, as well as waste management. However, mine operators are nowadays facing important challenges of various kinds: economical, technological, societal, and environmental. This has led the mining sector to decrease significantly in some areas of the earth globe, such as in Europe. In addition, the mining industry is not immune to mineral resources price volatility, which increases its vulnerability.

Moreover, the mining industry is characterized by a certain conservatism in the face of practices evolution, and this is true wherever the localities around the world. Another deficit that characterizes the mining industry consists of a proven lack of communication between the main components of the mining operation: namely, the services of geology, mining and extraction, ore treatment and resource beneficiation, and, finally, the management of the various mining wastes, as well as the environmental management of the whole site to limit its impact on the surrounding area. Regarding environmental impacts, mine operators are increasingly suffering from a sad image related to important environmental liabilities and difficult societal acceptance. In fact, mine exploitations are still obeying the linear economy scheme consisting of the extraction of finite ore resources and the production of a high volume of various solid wastes ("take-make-dispose"), where the only profits are those of the valuable minerals. For this reason, legislation and policies nowadays keep evolving to become increasingly binding regarding mine waste management practices and rules, towards waste preservation from weathering and pollution release. These issues become integrated into the whole mining life cycle; upstream since the exploration and feasibility steps, during mining and extraction, along ore processing and waste flowsheets.

The mining industry, in addition to well-known countries like China, Russia, Australia, Canada, the USA, and South Africa, is becoming more and more significant in new areas of the world, such as Latin America and Africa. This fact will prompt the new mining countries to encourage research and development, innovation as well as scientific research.

On the other hand, all resources prices including metals and industrial minerals have always been increasing since the 1960s, despite some conjectural variations (Figure 1). What is well correlated with this trend is the regular increase in the world consumption of these resources (Figure 2), despite the resources recycling increase. This is also true concerning what has become critical or strategic resources (rare earth elements, lithium, carbon, etc.) feeding many high value added industries in the last two decades (high technologies, energy storage, aeronautics, etc.).

One can also notice, besides these resource exploitation and consumption increases, a meteoric increase in the scientific contribution related to the mining sector, as shown in Figure 3. In fact, documents related to mining have increased from very few thousands in the 1960 s to more than 80,000 in the past decade. Leading countries in scientific contributions are still the USA and China immediately after-the most industrialized countries. Most of the top ten countries belong to the G7 world group (Figure 4). 


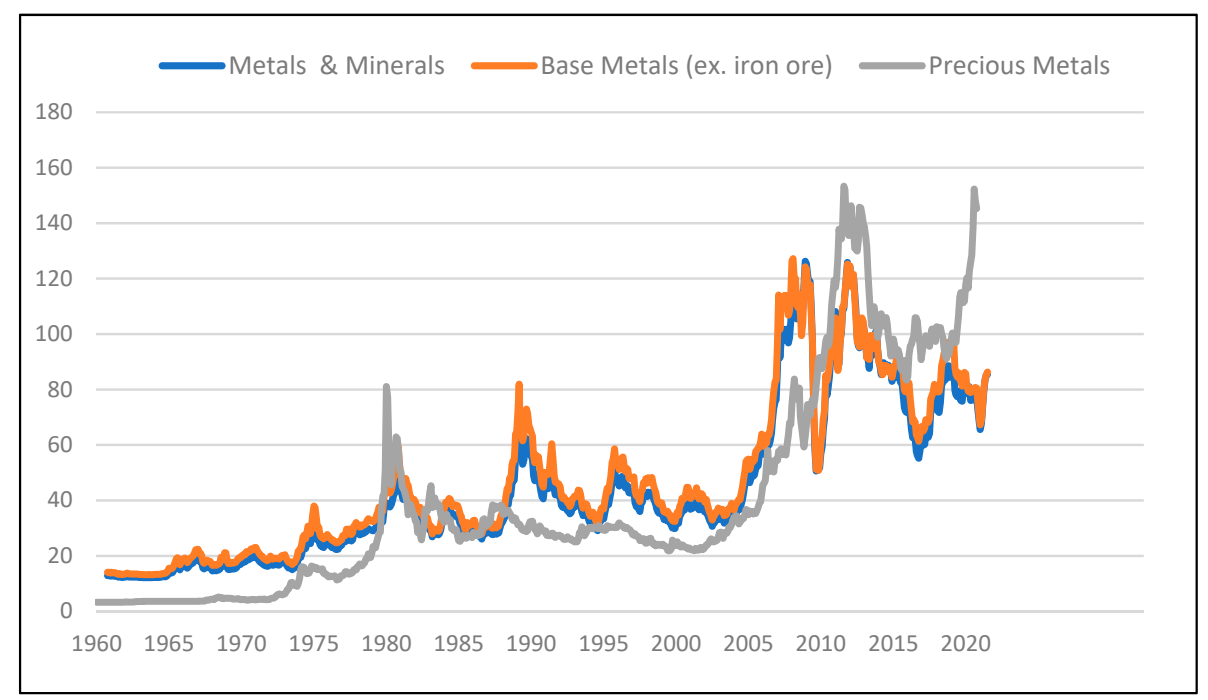

Figure 1. Indices of metal indices between 1960 and 2015 (Source World Bank Commodity Price Data [1]). Monthly indices based on nominal US dollars, $2010=100,1960$ to 2020.

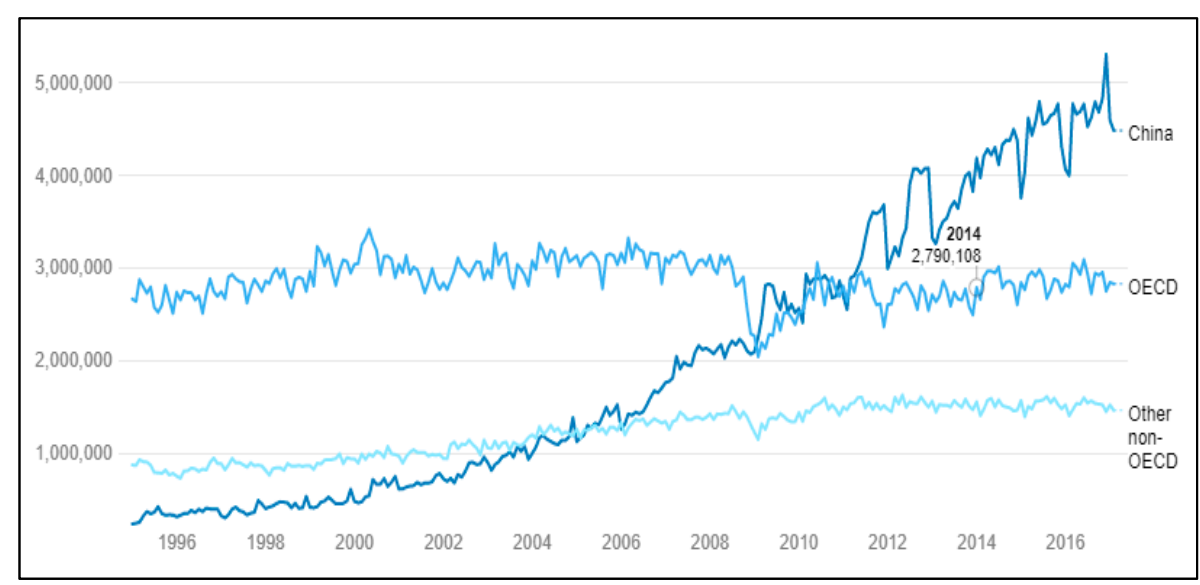

Figure 2. World refined metals consumption between 1995 and 2015 (Source Commodity Markets Outlook [2]).

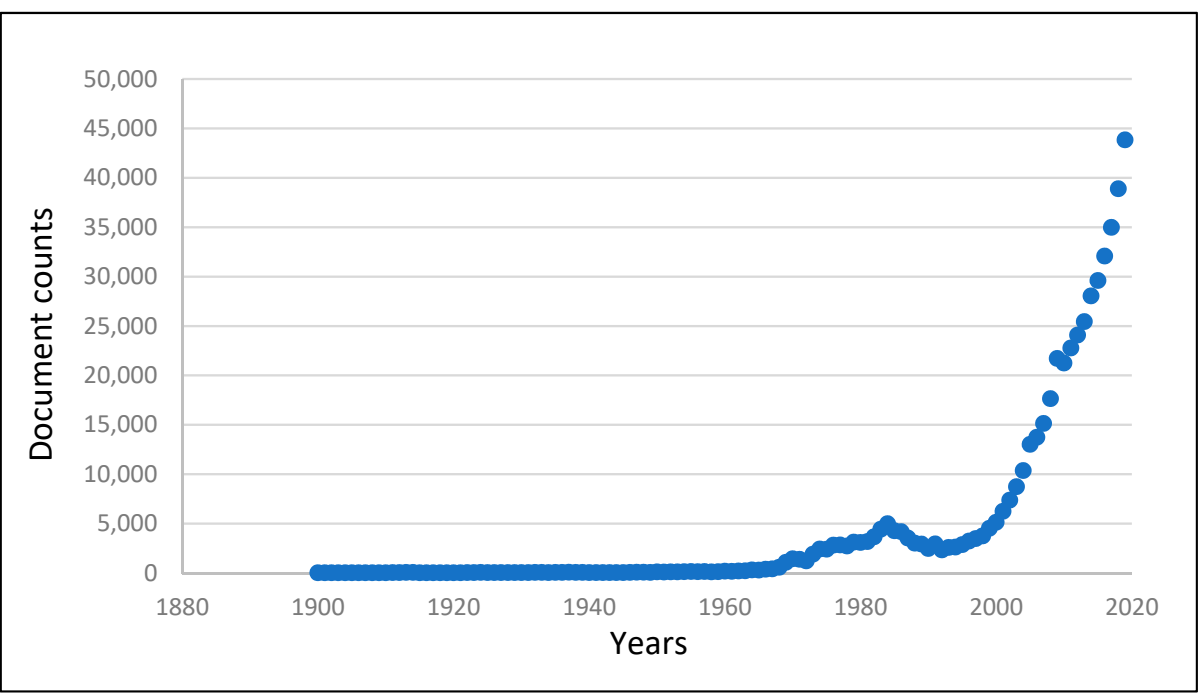

Figure 3. Evolution of yearly scientific documents production since 1900 (Source Scopus, Key words Mining or Mine). 


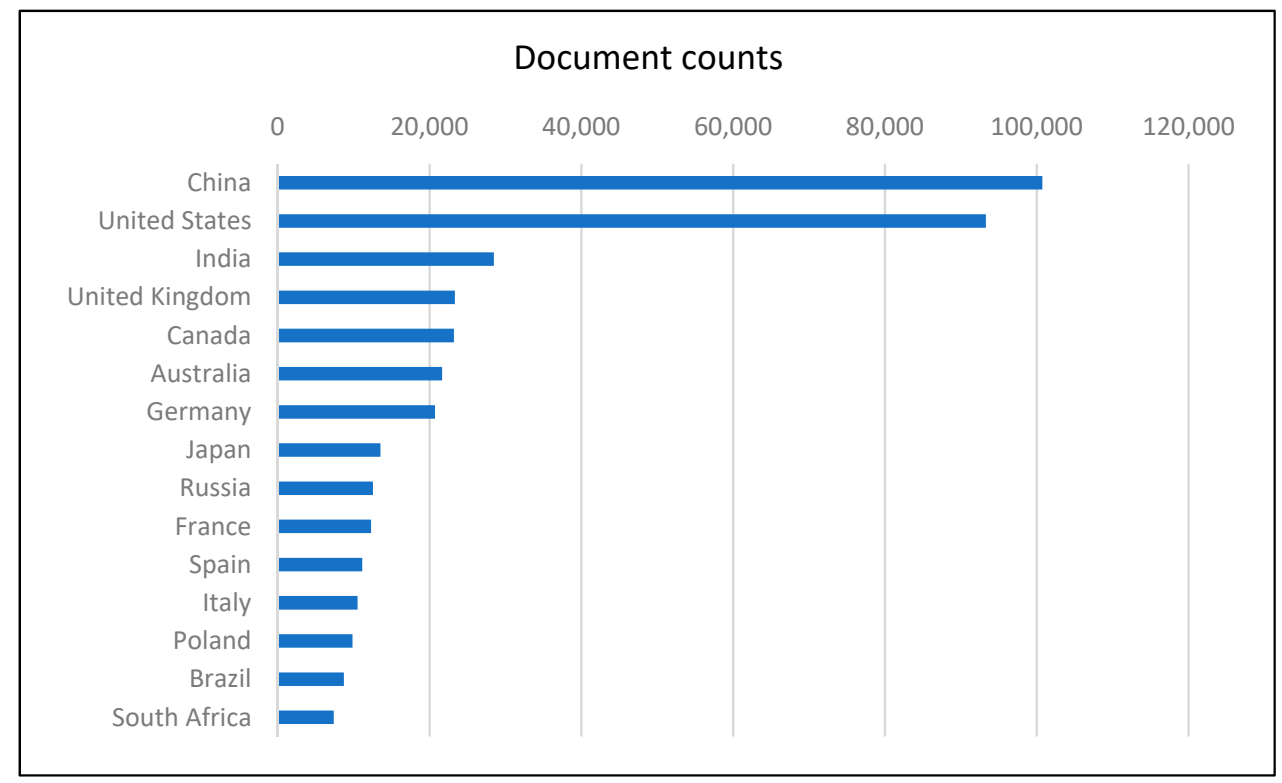

Figure 4. Documents total counts for the top 15 countries (Source Scopus, Key words Mining or Mine).

Its also important to notice that mining sciences are not well represented in terms of editions. To the knowledge of the EiC, there is no well-established journal to cover the mining sector as a whole. MDPI have launched the Minerals (https:/ / www.mdpi.com/ journal/minerals) and Metals (https://www.mdpi.com/journal/metals) journals, which are very popular, but remain focused on minerals or metals and do not represent the specific mining interests of readers. For this reason, Mining, as a new journal, could fill an important gap with scientific contributions in the field of mining, covering all its components (geology; mine and extraction; ore processing and beneficiation; environmental management) and the whole mining life cycle (exploration; feasibility; construction; operation; closure). Geometallurgical approaches that are leading the modern mining operation around the world are in fact very integrated and provisional approaches, allowing mine projects to be built more strongly, taking minimal risks and enhancing profits while respecting the environment and the societies where they evolve.

So, contributions from all mining-related fields will be accepted as original papers, technical notes, discussions, and responses, in the regular issues or in Special Issues on selected issues related to important mining topics to be managed by guest editors. Figure 5 as well as the scope of the journal will provide all authors who are interested in publishing in Mining about the main specific area and topics covered by the journal. 


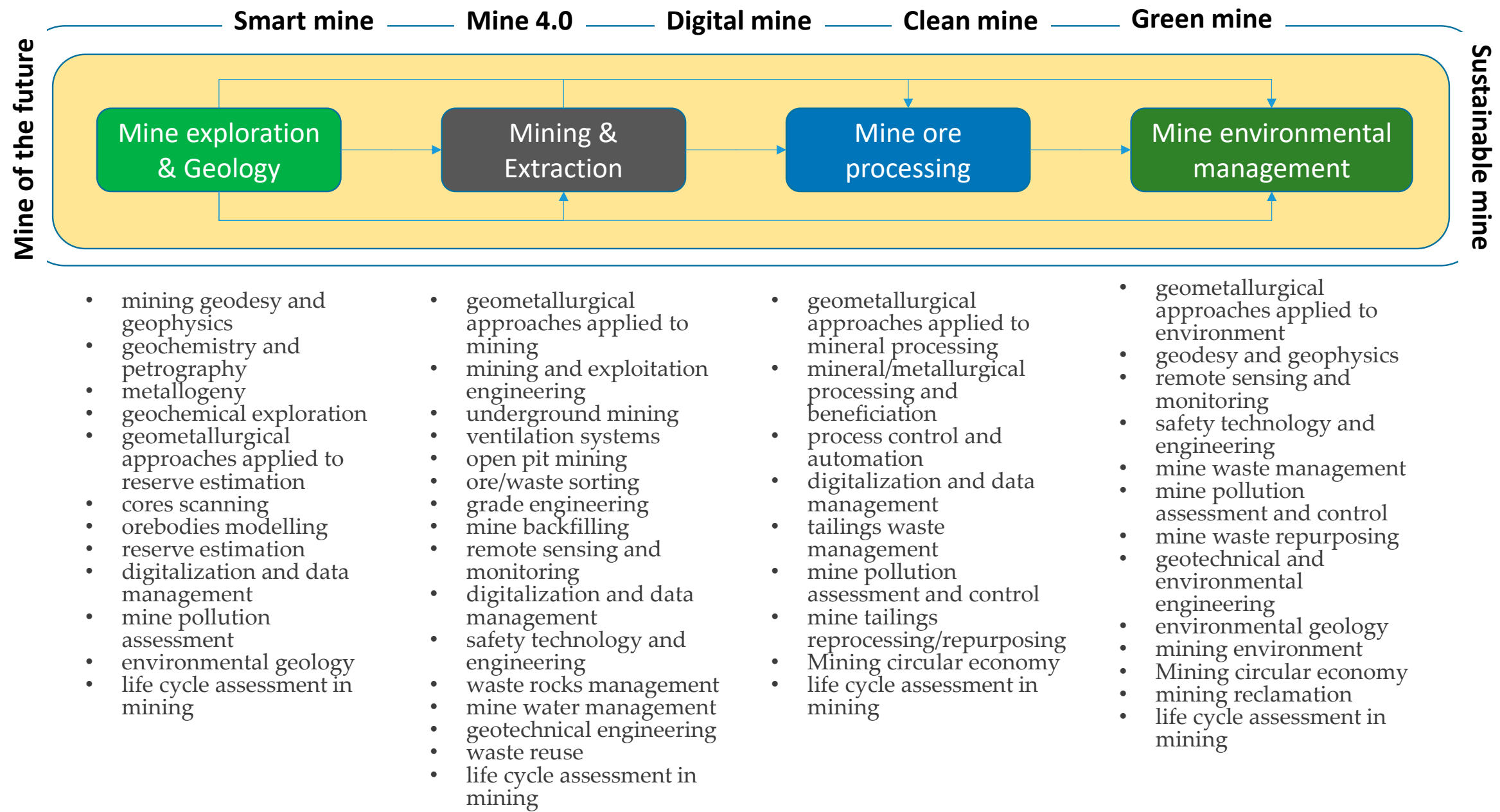

Figure 5. The main specific area and topics covered by Mining. 
With all board members, MDPI support, carefully selected reviewers, and "scientific miners" all around the world, we wish a great success to our journal Mining.

Conflicts of Interest: The author declares no conflict of interest.

\section{References}

1. The World Bank. Commodity Markets. 2020. Available online: https://www.worldbank.org/en/research/commodity-markets (accessed on 12 November 2020).

2. John, B. The Global Commodities Outlook in Nine Charts. World Bank Blogs (Let's Talk Development). 2017. Available online: https://blogs.worldbank.org/developmenttalk/global-commodities-outlook-nine-charts (accessed on 12 November 2020).

\section{Short Biography of Author}

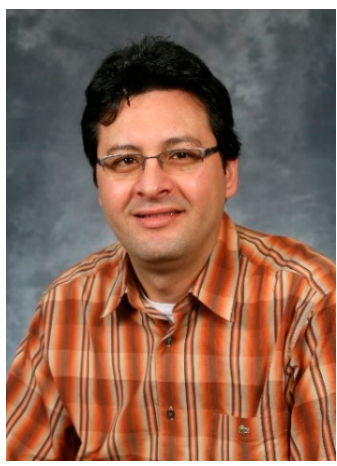

Mostafa Benzaazoua obtained a Ph.D. in the fields of "Geosciences and Environment" in 1996 at University of Lorraine-Ecole Nationale de Géologie Nancy (France). Then, he joined the University of Quebec (UQAT) in 1996 as postdoctoral fellow. He became UQAT professor in 1997 and held a Canada Research Chair (CRC 2003-2011) on "Mine waste integrated management". In 2009, he co-chaired an International Research Chair funded by the International Development Research Centre (IDRC) jointly with the CRC program jointly with UCA Marrakech University (Morocco). Now, he is a Visiting professor at Wuhan Institute of Technology in China (WIT) and Affiliated Professor at University Mohamed VI Polytechnic (UM6P) animating its Program EMEC (Mining Environment and Circular economy). Since 1992, he worked on large number of government funded and industry sponsored research projects dealing with mineralogy and geochemistry applied to mine and industrial pollution control, waste management stabilization and valorization, mine site reclamation and mineral/waste re/processing. He is also, since 2008, member of the CRIB (Research center on concrete infrastructures). He published more than 170 journal papers and (co-)supervised more than 70 students at the Master and PhD levels. 